\title{
Severity of chronic pain in an elderly population in Sweden-impact on costs and quality of life
}

Lars Bernfort, Björn Gerdle, Mikael Rahmqvist, Magnus Husberg and Lars-Åke Levin

\author{
Linköping University Post Print
}

Tweet

N.B.: When citing this work, cite the original article.

Original Publication:

Lars Bernfort, Björn Gerdle, Mikael Rahmqvist, Magnus Husberg and Lars-Åke Levin, Severity of chronic pain in an elderly population in Sweden-impact on costs and quality of life, 2015, Pain, (156), 3, 521-527.

http://dx.doi.org/10.1097/01.j.pain.0000460336.31600.01

Copyright: Elsevier / Lippincott, Williams \& Wilkins http://www.elsevier.com/

Postprint available at: Linköping University Electronic Press

http://urn.kb.se/resolve?urn=urn:nbn:se:liu:diva-116965 


\title{
Severity of chronic pain in an elderly population in Sweden-impact on costs and quality of life
}

\author{
Lars Bernfort $^{\mathrm{a}, \star}$, Björn Gerdle ${ }^{\mathrm{b}, \mathrm{c}}$, Mikael Rahmqvist ${ }^{\mathrm{a}}$, Magnus Husberga ${ }^{\mathrm{a}}$, Lars-Åke Levin ${ }^{\mathrm{a}}$
}

\begin{abstract}
Chronic pain is associated with large societal costs, but few studies have investigated the total costs of chronic pain with respect to elderly subjects. The elderly usually require informal care, care performed by municipalities, and care for chronic diseases, all factors that can result in extensive financial burdens on elderly patients, their families, and the social services provided by the state. This study aims to quantify the societal cost of chronic pain in people of age 65 years and older and to assess the impact of chronic pain on quality of life. This study collected data from 3 registers concerning health care, drugs, and municipal services and from 2 surveys. A postal questionnaire was used to collect data from a stratified sample of the population 65 years and older in southeastern Sweden. The questionnaire addressed pain intensity and quality of life variables (EQ-5D). A second postal questionnaire was used to collect data from relatives of the elderly patients suffering from chronic pain. A total of $66.5 \%$ valid responses of the 10,000 subjects was achieved; $76.9 \%$ were categorized as having no or mild chronic pain, $18.9 \%$ as having moderate chronic pain, and $4.2 \%$ as having severe chronic pain. Consumed resources increased with the severity of chronic pain. Clear differences in EQ-5D were found with respect to the severity of pain. This study found an association between resource use and severity of chronic pain in elderly subjects: the more severe the chronic pain, the more extensive (and expensive) the use of resources.
\end{abstract}

Keywords: Age, Costs, Elderly, Intensity, Pain, Severity

\section{Introduction}

By 2050, 30\% of the European population will be aged 65 years or older. ${ }^{10}$ The European Commission has the goal to increase the average number of healthy life years in the European Union, a goal that requires addressing chronic pain in the elderly. ${ }^{32}$ There is no consensus with respect to the relationships between prevalence of chronic pain and age; some studies note an increase in pain with age, some a decrease with age, some a peak in middle age, and some found no age dependence. ${ }^{15,19,29,33}$ In addition, a systematic review and a later study reported that only the prevalence of severe pain conditions increased with age. ${ }^{15,45}$

The literature suggests that the prevalence of chronic musculoskeletal pain conditions in the elderly varies considerably. In a short Swedish epidemiologic study not specifically focused on the elderly population, the prevalence of chronic pain (irrespective of pain intensity) was 56\% among people aged 65

Sponsorships or competing interests that may be relevant to content are disclosed at the end of this article.

a Division of Health Care Analysis, Department of Medical and Health Sciences, Linköping University, Linköping, Sweden, Departments of ${ }^{b}$ Pain and Rehabilitation Centre and, ${ }^{c}$ Department of Medical and Health Sciences, Linköping University, Linköping, Sweden

${ }^{*}$ Corresponding author. Address: Department of Medical and Health Sciences, Linköping University, SE-581 85 Linköping, Sweden. Tel.: +46 1034987; fax: +46 1034995. E-mail address: lars.bernfort@liu.semailto (L. Bernfort).

PAIN 156 (2015) 521-527

(C) 2015 International Association for the Study of Pain. This is an open-access article distributed under the terms of the Creative Commons Attribution-NonCommercialNoDerivatives 3.0 License, where it is permissible to download and share the work provided it is properly cited. The work cannot be changed in any way or used commercially

http://dx.doi.org/10.1097/01.j.pain.0000460336.31600.01 years and older, ${ }^{24}$ but other studies report a higher prevalence of pain in older adults (60\%-86\%). ${ }^{34,35} \mathrm{~A}$ recent review concluded that it was not possible to provide a general estimate because of heterogeneity of the studies. ${ }^{20}$

Chronic pain is associated with large societal costs. The total cost of moderate-to-severe chronic pain for Swedish society in 2003 was calculated to be 87.5 billion SEK, of which 7.5 billion SEK consisted of direct health care costs and 80 billion SEK consisted of indirect costs related to production loss because of illness-related sick leave. ${ }^{44}$ In another Swedish study concerning diagnoses possibly related to pain, the total costs were 4 times higher. ${ }^{26}$ In both studies, the indirect costs constituted the majority of costs. Some studies, including studies that focus on health care use, indicate that very large costs are associated with chronic pain and especially severe chronic pain. ${ }^{12,18,23,27,40}$ However, very little is known about health care costs in the elderly population. Obviously, the elderly rarely require sick leave, so these costs are marginal. However, costs related to informal care and care performed by municipalities may be significant for this age group. Moreover, increased age is associated with increased prevalence of chronic diseases and co- and multimorbidities, 3,38 complications that require more complex health care and greater personal and state expenses.

Although a relationship between pain and low quality of life $(\mathrm{HRQOL})$ has mainly been reported in middle-aged cohorts, little is known about this relationship in the elderly. ${ }^{32}$ This is the first report of an epidemiologic study aimed at investigating the elderly population with respect to the prevalence, intensity, variability, and frequency of pain and how such pain characteristics correlate with sociodemographic factors, comorbidities, activities, and health. To this end, this study quantifies societal costs for chronic 
pain care for people 65 years and older. In addition, this study investigates the relationship between chronic pain and HRQoL.

\section{Methods}

\subsection{Design and subjects}

This study collected data from 3 registers and 2 surveys. The first survey was a cross-sectional postal questionnaire used to collect data from a stratified sample of elderly-65 to 69 years, 70 to 74 years, 75 to 79 years, 80 to 84 years, and 85 years and older - residing in the 2 largest cities of a county (Östergötland) in southeastern Sweden. These subjects were selected from a sampling frame based on the Total Population Register. A questionnaire was mailed in October 2012 and was followed by up to 2 postal reminders (at 2-week intervals). The collection of questionnaires closed in January 2013. Data were collected by Statistics Sweden (SCB). The sample population consisted of 49,320 people. From this sample, 2000 subjects were randomly selected from each age stratum, so the final study included 10,000 subjects. The first survey asked the subject whether they needed help from relatives because of their chronic pain. If they answered "yes," then a second postal survey was sent to the relative(s) mainly responsible for their care. Two postal reminders (at 2-week intervals) were also mailed for the second survey.

The study was approved by the Regional Ethics Research Committee in Östergötland, Sweden (Dnr: 2012/154-31).

\subsection{Main questionnaire}

The questionnaire sent to the elderly subjects included several variables and instruments. All variables and instruments will be described in detail in forthcoming studies. This study used the pain intensity and quality of life variables described below.

\subsection{Pain intensity}

The respondents assessed their pain intensity by marking an 11grade (0-10) numeric rating scale; zero indicated no pain at all and 10 indicated worst possible pain. ${ }^{21}$ For analytical purposes, the population was subdivided into 3 groups with respect to having chronic pain or not and with respect to level of pain during the last week: no or mild pain (0-4), moderate pain (5-7), or severe pain (8-10). ${ }^{6,28}$ An alternative approach to using numbers with 2 verbal anchor points is to label different sections of the scale with verbal descriptions such as "mild," "moderate," and "severe" chronic pain. ${ }^{14,36}$ The reason for this approach would be that such labels may more adequately represent the respondents' perceptions. However, in this study, we choose to follow the recommendations of IMMPACT and used numeric rating scale with 2 anchor points. ${ }^{17}$

\subsection{Quality of life}

In the main questionnaire, the instrument EQ-5D for measuring health-related quality of life was included. The EQ-5D instrument is a descriptive system of health-related quality of life states consisting of 5 dimensions-mobility, self-care, usual activities, pain/discomfort, and anxiety/depression. For each dimension, the subject records the level of severity-no problems/some or moderate problems/extreme problems. ${ }^{1,8}$ Each combination (denoted EQ-5D profile) can be transformed into an index value corresponding to a quality-adjusted life-year weight using the UK population-based value set. ${ }^{16}$ The EQ-5D also contains a visual analog scale (VAS) health scale (denoted EQ-5D-VAS) that ranges between 0 and 100, where zero is the worst imaginable health state and 100 is the best imaginable health state. The EQ-5D-VAS is an alternative direct method for eliciting an index value. This study presents results for both the EQ-5D-index (including the 5 items) and EQ-5D-VAS.

\subsection{The relatives' questionnaire}

In the main questionnaire, the respondents were asked to volunteer contact information for relatives who provided them informal care and support. If the respondents volunteered contact information, a second questionnaire was mailed to the relatives who they identified as their main caregivers. This second questionnaire asked these relatives about what kind of support they provided and how many hours they spent caring for their elderly relative. This support included domestic chores, shopping, getting around outside the home, taking medication, and handling finances. These caregivers were also asked to estimate the amount of work time and leisure time they devoted to their charges.

\subsection{Informal care costs}

Informal care costs were calculated according to the human capital approach. ${ }^{49}$ The cost of a workday spent caring for the relative was calculated as average gross wages (Sweden, 2012) plus payroll taxes (230 EUR corresponding to 29 EUR per hour). ${ }^{1}$ Leisure time was valued as half the average net wages (7.78 EUR per hour).

\subsection{The health care registers used for retrieving health care costs}

Registers were used to retrieve information on consumption of health care and health care costs. Data on inpatient (hospital days and treatments) and outpatient (visits to various categories of personnel) care were retrieved from the Health Care Register in Östergötland (HCRÖ). The HCRÖ is an administrative database that records date, name, unique personal identification number, and diagnosis (main diagnosis and up to 9 secondary diagnoses) according to the International Classification of Diseases, 10th version (ICD-10), of every health care visit or hospital stay within the County of Östergötland. This database has previously been described in greater detail. ${ }^{50}$ The health care consumption related to the persons participating in this study was retrieved from the HCRÖ by matching the personal ID numbers to the database. To determine costs, we linked health care consumption data from the HRCÖ with data in a regional cost database provided by Östergötland County Council. The regional cost per patient database contains costs for all health care services within Östergötland County and, combined with the CDWÖ, offers individual-based cost data that may be summarized for certain populations or clinics.

The National Board of Health and Welfare (Socialstyrelsen) maintains a register on drug prescription. The register contains information on prescribed medications that have been retrieved by patients. The register can be merged with other registers to connect prescribed and retrieved drugs to specific diagnoses or individuals. For each prescription, the drug register contains information on the patient, prescribed drug, relevant diagnosis, cost, profession, and workplace. Information on all prescribed and then retrieved drugs related to the participants in our study were gathered by matching the personal ID numbers to the register.

Information on costs incurred by the municipalities for home help services and special housing was retrieved from a register provided by the Linköping municipality. The register contains all 
consumption of the different home help services with hours and prices attached to each service. In addition, the register contains the number of days in special housing. Total costs can be calculated by the use of the standard cost per day. The municipal registers also contain personal ID numbers, which were used to match the data to persons participating in our study. All costs are expressed as costs per year (2012 prices). Cost data were gathered over 1 year, from November 2011 to October 2012.

\subsection{Statistics}

All data files and analyses of data were handled with SPSS version IBM Statistics 20 (IBM Corp., Armonk, NY). The outcome in costs for the 3 chronic pain groups was tested using analysis of variance, and the result was adjusted for sex and age. The age component, in particular, should be adjusted when testing the different costs across the groups. Analysis of variance was used for the statistical analysis of costs for health care, drug acquisition, and municipal home services. The $P$ value was $\leq 0.05$.

\section{Results}

\subsection{Participation rate}

Of the 10,000 subjects selected from the sample population, 3261 did not participate or did not return the questionnaire; 58 of these subjects were not reachable. The net response rate was $67.3 \%$; however, some respondents failed to answer a number of vital questions, leaving a total of 6611 (66.5\%) valid responses.

\subsection{Characteristics of the responders}

The valid study population (6611 subjects) consisted of $54 \%$ women and $46 \%$ men. Average age was 76.2 years (range, $65-102$ years). The intensity of chronic pain broke down as follows: $76.9 \%$ were categorized as having no or mild chronic pain, 18.9\% as having moderate chronic pain, and $4.2 \%$ as having severe chronic pain.

\subsection{Comparisons between responders and nonresponders}

Results were calibrated with respect to imbalances in responsiveness associated with certain variables. Calibrations were made for results to be representative of the population studied. Table 1 shows variation in responsiveness for the most important background variables.

\subsection{Costs}

Results on resource uses are presented in Table 2. The total average annual cost to society in terms of health care, drugs, municipal services, and informal care for the average person 65 years or older was 5090 EUR. It is clear that the more severe the chronic pain, the more resources were consumed (Table 2). The additional costs of chronic pain that was more severe than mild, that is, for moderate and severe chronic pain, were on average 570 EUR SEK per person 65 years and older. The total annual costs were more than doubled in the subgroup with severe chronic pain compared with the group with no or mild chronic pain (ie, 10,200 EUR vs 4510 EUR). Moderate chronic pain also showed a higher cost than no or mild chronic pain (ie, 6250 EUR vs 4510 EUR). Health care costs generally increase with both age and severity of chronic pain, as presented in Figure 1.

With the exception of municipal costs, the statistical analyses showed highly significant differences between the groups for the
Table 1

\section{Proportion responding with respect to different} characteristics.

\begin{tabular}{lc}
\hline Characteristics & Response rate, \% \\
\hline Gender & 73.1 \\
Men & 66.0 \\
Women & \\
Age & 74.9 \\
$65-69$ & 75.4 \\
$70-74$ & 70.7 \\
$75-79$ & 64.0 \\
$80-84$ & 51.1 \\
85 and above & \\
Marital status & 75.5 \\
Married & 61.5 \\
Other & \\
Education & 59.2 \\
Compulsory school & 72.2 \\
Secondary school & 82.5 \\
University & \\
Income (SEK per y) & 57.0 \\
0-150,000 & 69.1 \\
150,001-220,000 & 80.8 \\
220,001 and above & \\
Birth country & 71.1 \\
Sweden & 54.8 \\
Rest of Europe & 33.2 \\
Rest of the world & \\
\hline
\end{tabular}

investigated cost items (Table 2). However, when municipal costs were divided according to home help services and special housing, the tests indicate differences concerning home help services but not special housing.

In the first questionnaire, 249 respondents stated that they received help from relatives. In the relatives' questionnaire, 128 relatives completed the questionnaire: $38(30 \%)$ were relatives of persons with no or mild chronic pain, 55 (43\%) were relatives of persons with moderate chronic pain, and 35 (27\%) were relatives of persons with severe chronic pain. The costs of the subgroup of help receivers were distributed over the entire study population of 6611 persons. The results clearly show that increased severity of chronic pain is associated with increased informal care costs.

When interpreting results from surveys, caution should be taken regarding the representativeness of the respondents. In this study, particular caution should be taken in interpreting results considering informal care costs as the number of elderly persons reporting to receive help from relatives was relatively small. In addition, the response rate among relatives identified as helpers was relatively low. These facts might indicate that informal care costs were underestimated.

\subsection{Quality of life}

The health-related quality of life of persons with different grades of chronic pain measured by EQ-5D is presented in Table 3. Differences in health-related quality of life were very clear between the 3 pain categories, both for the EQ-5D-index and the EQ-VAS, and for each of the 5 dimensions of the EQ-5D-health state profile. The least evident difference concerns the dimension of self-care (Table 3). The differences detected clearly show the association between presence and degree of chronic pain and the health-related quality of life experienced.

EQ-5D-index values for persons with different levels of chronic pain in different age groups are presented in Figure 2. Generally, 
Table 2

Mean annual health care and municipal costs (Euros, rounded to the nearest 10) per person across subgroups with different conditions of chronic pain.

\begin{tabular}{|c|c|c|c|c|}
\hline Average cost (CI 95\%) & $\begin{array}{l}\text { Without pain or with mild } \\
\text { chronic pain }(n=5077)\end{array}$ & $\begin{array}{l}\text { Moderate chronic pain } \\
(n=1245)\end{array}$ & $\begin{array}{l}\text { Severe chronic pain } \\
(n=289)\end{array}$ & $P$ \\
\hline Inpatient care & $1220(1030-1410)$ & 1710 (1330-2090) & 2110 (1320-2900) & 0.012 \\
\hline \multicolumn{5}{|c|}{ Outpatient and primary care } \\
\hline Doctor's visits & $1230(1160-1300)$ & $1760(1610-1900)$ & $2000(1700-2300)$ & $<0.001$ \\
\hline Total outpatient care & $1710(1610-1800)$ & $2500(2300-2700)$ & 3100 (2690-3500) & $<0.001$ \\
\hline Drugs & $440(410-480)$ & $640(580-710)$ & $900(760-1040)$ & $<0.001$ \\
\hline Total health care & $3370(3120-3610)$ & $4860(4360-5360)$ & $6110(5080-7130)$ & $<0.001$ \\
\hline Home help services & $280(180-370)$ & $340(170-520)$ & $1180(800-1560)$ & $<0.001$ \\
\hline Special housing & $680(530-810)$ & $530(240-820)$ & 1200 (610-1790) & 0.136 \\
\hline Total municipal costs & 960 & 80 & 2380 & NA \\
\hline Informal care & 180 & 520 & 1710 & NA \\
\hline Total costs & 4510 & 6250 & 10,200 & NA \\
\hline
\end{tabular}

$\mathrm{NA}=$ not applicable.

the expected relationship of lower HRQoL with increasing age can be seen. The most remarkable result is the very low HRQoL (0.2) experienced by those with severe chronic pain in the oldest age group.

\section{Discussion}

This study found that both costs and the aspects of HRQoL investigated were clearly associated with the existence and severity of chronic pain. This relationship was evident for all kinds of resource use. Hence, health care costs and HRQoL aspects differed significantly between the 3 groups-no or mild, moderate, and severe chronic pain.

As briefly reviewed by Lalonde et al., ${ }^{31}$ economic burden increases with pain severity and/or pain disability. This observation was confirmed in this study's population, elderly subjects. Our results indicate that the cost to society in terms of health care, drugs, municipal services, and informal care for the average person 65 years or older with or without chronic pain is 5090 EUR per year. The municipalities studied together have approximately 50,000 inhabitants 65 years and older, which would translate into a total cost of 255 million EUR, assuming that the 2 municipalities are representative for Sweden (approximately 1.8 million inhabitants 65 years and older). This would imply that costs attributable to people 65 years and older add up to 9.2 billion EUR for Sweden. These costs can be seen as the cost of an aging population.

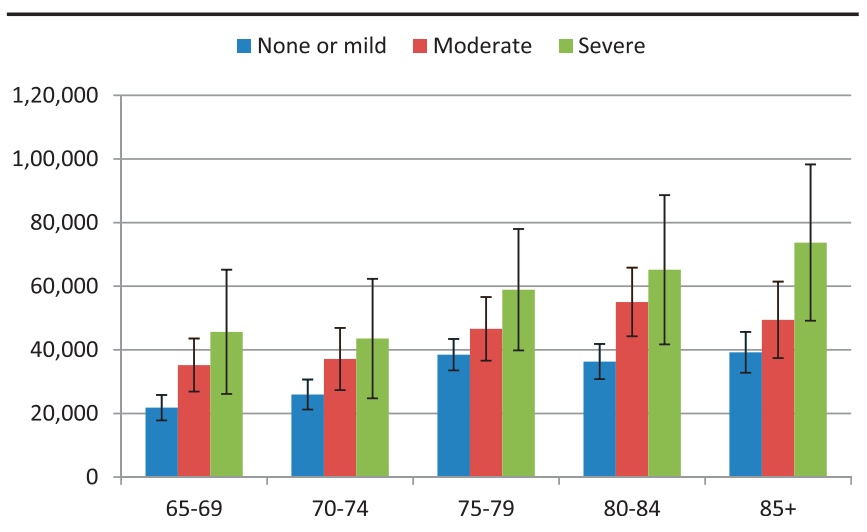

Figure 1. Health care costs divided into different age groups categorized with respect to the level of chronic pain, and it shows the variation in health care costs because of age and divided into groups of severity of chronic pain.
The additional cost associated with moderate and severe chronic pain was on average 570 EUR per person 65 years and older. This means that for Linköping and Norrköping together the additional annual costs of the presence of chronic pain that is worse than mild is $\mathbf{2 8 . 5}$ million EUR. This cost difference means that for Sweden (10 million citizens) the additional annual costs for chronic pain worse than mild in people 65 years and older amounts to more than 1 billion EUR.

In a Swedish study, Gustavsson et al. ${ }^{26}$ estimated the direct and indirect costs of patients with a diagnosis related to chronic pain. The mean total cost per patient each year was estimated at 6400 EUR (SEK 56,000); this study found the mean total cost per year of persons 65 years or older to be 5090 EUR. The estimation of diagnosis related to chronic pain is not intended to estimate the costs of pain, as many diagnoses are not associated with pain, a confounder that could lead to an overestimation. Gustavsson et al. $^{26}$ discussed possible reasons for this discrepancy and pointed out the difficulty of strictly dividing the costs into painrelated and nonpain-related costs. From an international perspective, many cost estimations are hampered by difficulties identifying patients with chronic pain. ${ }^{7}$ Thus, a strength of our epidemiologic population-based study is that the pain classification is based on the respondents' own evaluations.

Outpatient care costs are most reasonably underestimated because of the fact that data from private caregivers were not included in the data capture. However, private care is generally only a small part of the total health care in the 2 municipalities investigated. A fact that distinguishes this study from other similar ones is that we have been able to include costs incurred by the municipalities, making this study more complete compared with its predecessors. However, municipal costs could only be retrieved from one (Linköping) of the 2 included municipalities. Concerning the municipal costs, the group with the most severe chronic pain stands out as a large consumer of resources. Differences in municipal costs between the group with no or mild chronic pain and the group with moderate chronic pain were quite small, possibly because of the elderly population consuming resources irrespective of the existence of chronic pain. Chronic pain may become a problem only for the group with the most severe chronic pain.

A possible weakness in the study lies in the data quality on informal care. In the relatives' questionnaire, some internal loss of data was experienced. A related issue is how to value the relatives' loss of leisure time because of informal care efforts. Equating loss of production with loss of time from paid labor would imply that the value of leisure time is zero. We do not agree 
Table 3

Health-related quality of life measured by EQ-5D for the defined subgroups with different severity of chronic pain.

Dimensions of EQ-5D

Persons without or with mild chronic pain (0-4)

\begin{tabular}{|c|c|c|c|c|}
\hline & $\begin{array}{l}\text { Alternatives, } \\
\mathrm{N}\end{array}$ & $\overline{1}$ & 2 & 3 \\
\hline Mobility & 6530 & $76.0 \%$ & $23.7 \%$ & $0.3 \%$ \\
\hline Self-care & 6545 & $95.8 \%$ & $3.0 \%$ & $1.2 \%$ \\
\hline Usual activities & 6487 & $92.1 \%$ & $5.8 \%$ & $2.1 \%$ \\
\hline Pain/discomfort & 6520 & $40.9 \%$ & $57.9 \%$ & $1.2 \%$ \\
\hline Anxiety/depression & 6528 & $75.7 \%$ & $23.7 \%$ & $0.6 \%$ \\
\hline EQ-5D-index & $\begin{array}{l}\text { Average (Cl) } \\
\quad \mathrm{N}\end{array}$ & \multicolumn{3}{|c|}{$\begin{array}{c}0.812(0.806-0.818) \\
4895\end{array}$} \\
\hline $\begin{array}{l}\text { EQ-5D-VAS }(0- \\
100)\end{array}$ & $\begin{array}{l}\text { Average }(\mathrm{Cl}) \\
\mathrm{N}\end{array}$ & \multicolumn{3}{|c|}{$74.5(73.9-75.0)$} \\
\hline
\end{tabular}

100)
Persons with moderate chronic pain (5-7)

\begin{tabular}{lll}
\hline 1 & 2
\end{tabular}

Persons with severe chronic pain (8-10)

\begin{tabular}{lll}
\hline 1 & 2
\end{tabular}

$90.5 \%$

$78.2 \%$

$1.7 \%$

$58.2 \%$

$0.629(0.617-0.641)$

$60.9(59.8-62.1)$ 1191

1207

$53.5 \%$
$7.9 \%$
$17.9 \%$
$86.3 \%$
$40.3 \%$
$(0.617-0.641)$
1191
$9(59.8-62.1)$
1207

$1.1 \%$
$1.5 \%$
$3.9 \%$
$12.0 \%$
$1.5 \%$

$24.7 \%$

$77.5 \%$

$59.3 \%$

$1.5 \%$

$43.7 \%$
$0.385(0.360-0.410)$
263

$49.0(46.6-51.4)$

$\begin{array}{ll}73.1 \% & 2.2 \\ 15.7 \% & 6.8 \\ 28.2 \% & 12.5 \\ 53.5 \% & 45.1 \\ 48.4 \% & 7.9 \\ (0.360-0.410) \\ 263 \\ 0(46.6-51.4)\end{array}$

282

The 5 items of EQ-5D are shown in the proportions with respect to the answering alternative (1 generally denotes without difficulties, 2 generally denotes with some difficulties, and 3 generally denotes not able to or with very large difficulties or high intensity). The 2 bottom rows show the EQ-5D-index value based on the 5 items (including $95 \% \mathrm{Cl}$ ) and the EQ-VAS.

$\mathrm{Cl}$, confidence interval; EQ-VAS, EQ visual analog scale.

with setting the value at zero, as many elderly people produce economic value outside of paid labor. Therefore, the value of leisure time was set to half the average of the net hourly wage. Setting a lower value (or even zero) would, of course, affect our results, but not in a decisive way; the marked differences between the groups would persist.

Another limitation of this study with respect to costs is the generalizability as only 1 country has been investigated. Studies of fibromyalgia syndrome in the United States, France, and Germany showed differences in the proportion of direct costs between countries, ${ }^{30}$ which indicates that the relative importance of the different cost items may differ because of political traditions and social situations as well as arrangements of welfare and health care in the countries under investigation.

Patients with chronic pain conditions describe pronounced negative implications both on the individual level (eg, psychological problems and decreased emotional well-being) and on the societal level (eg, sick leave). ${ }^{11,37,42,47}$ A measure of nonfatal health outcomes from diseases and injuries is years lived with disability (YLDs). Pain conditions were responsible for $21 \%$ of all YLDs globally ${ }^{48}$ and the top 5 leading causes of YLDs in Sweden are low-back pain, major depressive disorder, falls, neck pain, and other musculoskeletal disorders. ${ }^{2}$ One striking result was the very large impact of the existence and severity of chronic pain on the quality of life both according to EQ-5D-index and EQ-5D-VAS in this study of elderly subjects. Cross-sectional analyses have

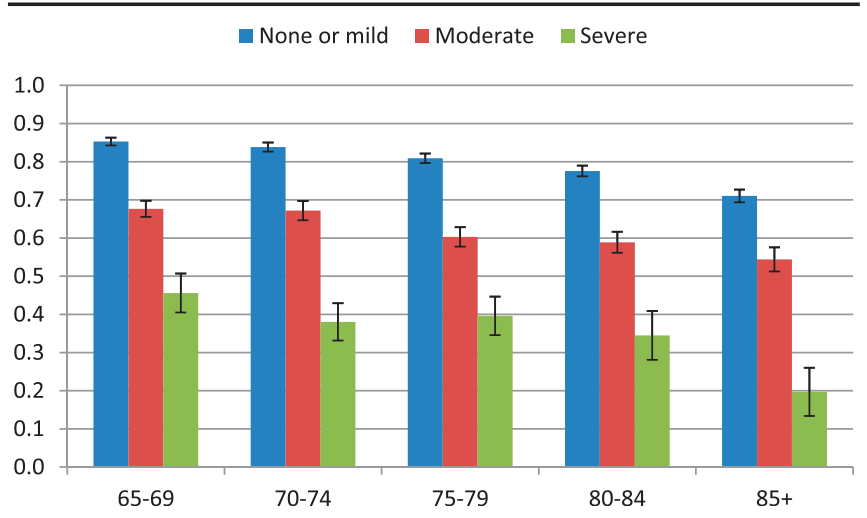

Figure 2. EQ-5D-index values divided into different age groups categorized with respect to level of chronic pain, and it shows the variation in HRQoL because of age and divided into groups of severity of chronic pain. reported a negative correlation between back pain and aspects of HRQoL. ${ }^{7,13,22,39,41,51}$ Such relationships have been found both in chronic pain cohorts and in population-based studies. 4,32,43 In addition, systematic reviews have confirmed evidence for a link between pain and low HRQoL. ${ }^{32,37}$ In a systematic review, Leadly et al. ${ }^{32}$ noted a lack of studies concerning the elderly population. According to the present results, a relationship between chronic pain and low HRQoL is also present in the elderly population. One of the systematic reviews reported a lack of evidence for a relationship between HRQOL and pain intensity ${ }^{37}$; however, our study found a relationship between $\mathrm{HRQOL}$ and pain intensity (Table 3). Hence, both quality of life aspects and costs were negatively associated with the presence and severity of pain in the elderly population. However, persons with more chronic pain may also be more likely to suffer from comorbidities that might explain some of the variations in costs and HRQoL. Moreover, HRQoL has previously been shown to decrease with age in a Swedish general population, ${ }^{9}$ for instance from 0.89 when 30 to 39 to 0.61 when 80 to 84 year old. So, our population mean of 0.76 (EQ-5Dindex) is as expected.

As pointed out by Breivik, ${ }^{5}$ several studies indicate that large indirect costs can be reduced if patients with complex chronic pain conditions are treated in multidisciplinary pain rehabilitation programs $^{46}$ and/or if reduction in severity of pain is accomplished. Generally, participation in multidisciplinary pain rehabilitation programs is offered to patients who are occupationally active (18-65 year old). It is unknown if such a treatment approach designed for elderly patients will be beneficial for the cost items investigated in this study. Furthermore, it is unclear if it is possible to reduce the severity of the pain condition in the relatively small subgroup with severe chronic pain. There is an obvious risk that comorbidities and multimorbidities are more prevalent in the severe pain group than in the 2 other groups. ${ }^{25}$ Subjects with comorbidity or multimorbidity have more complex health care needs than those with a single condition, ${ }^{38}$ which may indicate difficulties improving general health and eventually reducing costs. Because the presence of comorbidities, such as depression, seems to contribute to treatment resistance, future studies should investigate if and to what extent the prevalence of comorbidities differs across the pain groups and if comorbidities (including type) influence the cost within each pain group in the elderly population.

Although the response rate in this study was relatively high (67\%), there is a risk for 2 types of dropouts. There is a risk for underestimating the pain in those elderly unable to answer the questionnaire (eg, elderly treated in hospitals and nursing homes 
during the data collection period). The dropout analysis showed that this is probably the case as responsiveness declined with age, but response rate also declined with being female, being single, having a low education and low income, and being an immigrant. Another risk is that healthy subjects without pain will choose not to answer the questionnaire, a risk that this study's dropout analysis could not determine.

\section{Conclusions}

This population-based study, which reached a large part of the target population, found that the existence and the severity of chronic pain among people 65 year old and older were associated with increased costs to society and low quality of life.

\section{Conflict of interest statement}

This study was sponsored by a grant from Grünenthal Sweden $\mathrm{AB}$. The sponsor of the study had no role in study design, data collection, data analysis, data interpretation, writing of the report, or the decision to submit for publication. The authors had full access to all the data in the study and had final responsibility for the decision to submit for publication. The authors declare no conflicts of interest.

\section{Acknowledgements}

Author contributions: Design of the study: L. Bernfort, L.-Å. Levin, B. Gerdle. Statistical analyses: L. Bernfort, L. $-\AA$. Levin, M. Rahmqvist, M. Husberg. First draft of the manuscript: all authors. Comments on different and final versions of the manuscript: all authors. Approval of the final version of the manuscript: all authors.

\section{Article history:}

Received 16 October 2014

Received in revised form 5 December 2014

Accepted 9 December 2014

Available online 14 January 2015

\section{References}

[1] EuroQol: a new facility for the measurement of health-related quality of life. Health Policy 1990;16:199-208.

[2] Global Burden of Diseases, Injuries, and Risk Factors Study 2010-GBD Profile: Sweden 2014-07-05. Available from: www. healthmetricsandevaluation.org. Accessed 7 July, 2014.

[3] Barnett K, Mercer SW, Norbury M, Watt G, Wyke S, Guthrie B. Epidemiology of multimorbidity and implications for health care, research, and medical education: a cross-sectional study. Lancet 2012;380:37-43.

[4] Bjornsdottir S, Jonsson S, Valdimarsdottir U. Mental health indicators and quality of life among individuals with musculoskeletal chronic pain: a nationwide study in Iceland. Scand J Rheumatol 2014;43:1-15.

[5] Breivik $\mathrm{H}$. A major challenge for a generous welfare system: a heavy socio-economic burden of chronic pain conditions in Sweden-and how to meet this challenge. Eur J Pain 2012;16:167-9.

[6] Breivik H, Collett B, Ventafridda V, Cohen R, Gallacher D. Survey of chronic pain in Europe: prevalence, impact on daily life, and treatment. Eur J Pain 2006;10:287-333.

[7] Breivik H, Eisenberg E, O'Brien T, and on behalf of OPENminds. The individual and societal burden of chronic pain in Europe: the case for strategic prioritisation and action to improve knowledge and availability of appropriate care. BMC Public Health 2013;13:1229.

[8] Brooks RG. EuroQol: the current state of play. Health Policy 1996;37: 53-72.

[9] Burström K, Johannesson M, Diderichsen F. Health-related quality of life by disease and socio-economic group in the general population in Sweden. Health Policy 2001;55:51-69.
[10] Carone G, Costello D, Guardia N, Mourre G, Przywara B, Salomaki A. The economic impact of aging population in the EU25 Member States, in European Comission Economic Papers. Brussels: Directorate General for Economic and Financial Affairs, 2005.

[11] Casarett D, Karlawish J, Sankar P, Hirschman K, Asch DA. Designing pain research from the patient's perspective: what trial end points are important to patients with chronic pain? Pain Med 2001;2:309-16.

[12] Chandran A, Schaefer C, Ryan K, Baik R, McNett M, Zlateva G. The comparative economic burden of mild, moderate, and severe fibromyalgia: results from a retrospective chart review and crosssectional survey of working-age U.S. adults. J Manag Care Pharm 2012;18:415-26.

[13] Choi YS, Kim DJ, Lee KY, Park YS, Cho KJ, Lee JH, Rhim HY, Shin BJ. How does chronic back pain influence quality of life in koreans: a crosssectional study. Asian Spine J 2014;8:346-52.

[14] Collins S, Moore R, McQuay H. The visual analogue pain intensity scale: what is moderate pain in millimetres? PAIN 1997;72:95-7.

[15] Dionne CE, Dunn KM, Croft PR. Does back pain prevalence really decrease with increasing age? A systematic review. Age Ageing 2006;35: 229-34.

[16] Dolan P, Sutton M. Mapping visual analogue scale health state valuations onto standard gamble and time trade-off values. Soc Sci Med 1997;44: 1519-30.

[17] Dworkin RH, Turk DC, Farrar JT, Haythornthwaite JA, Jensen MP, Katz NP Kerns RD, Stucki G, Allen RR, Bellamy N, Carr DB, Chandler J, Cowan P, Dionne R, Galer BS, Hertz S, Jadad AR, Kramer LD, Manning DC, Martin S, McCormick CG, McDermott MP, McGrath P, Quessy S, Rappaport BA, Robbins W, Robinson JP, Rothman M, Royal MA, Simon L, Stauffer JW, Stein W, Tollett J, Wernicke J, Witter J. Core outcome measures for chronic pain clinical trials: IMMPACT recommendations. PAIN 2005;113: 9-19.

[18] Eriksen J, Sjogren P, Ekholm O, Rasmussen NK. Health care utilisation among individuals reporting long-term pain: an epidemiological study based on Danish National Health Surveys. Eur J Pain 2004;8:517-23.

[19] Fejer R, Leboeuf-Yde C. Does back and neck pain become more common as you get older? A systematic literature review. Chiropr Man Therap 2012;20:24.

[20] Fejer R, Ruhe A. What is the prevalence of musculoskeletal problems in the elderly population in developed countries? A systematic critical literature review. Chiropr Man Therap 2012;20:31.

[21] Ferreira-Valente MA, Pais-Ribeiro JL, Jensen MP. Validity of four pain intensity rating scales. PAIN 2011;152:2399-404.

[22] Froud R, Patterson S, Eldridge S, Seale C, Pincus T, Rajendran D, Fossum C, Underwood M, A systematic review and meta-synthesis of the impact of low back pain on people's lives. BMC Musculoskelet Disord 2014;15:50.

[23] Gaskin DJ, Richard P. The economic costs of pain in the United States. J Pain 2012;13:715-24.

[24] Gerdle B, Bjork J, Henriksson C, Bengtsson A. Prevalence of current and chronic pain and their influences upon work and healthcare-seeking: a population study. J Rheumatol 2004;31:1399-406.

[25] Grimby-Ekman A, Gerdle B, Björk J, Larsson B. Comorbidity, implications, and characteristics in local, regional, and widespread pain-a descriptive population-based survey. BMC Musculoskelet Disord; Submitted.

[26] Gustavsson A, Bjorkman J, Ljungcrantz C, Rhodin A, Rivano-Fischer M, Sjolund KF, Mannheimer C. Socio-economic burden of patients with a diagnosis related to chronic pain-register data of 840,000 Swedish patients. Eur J Pain 2012;16:289-99.

[27] Hauser W, Wolfe F, Henningsen P, Schmutzer G, Brahler E, Hinz A Untying chronic pain: prevalence and societal burden of chronic pain stages in the general population-a cross-sectional survey. BMC Public Health 2014;14:352.

[28] Hirschfeld G, Zernikow B. Variability of "optimal" cut points for mild, moderate, and severe pain: neglected problems when comparing groups. PAIN 2013;154:154-9.

[29] Hoy D, Brooks P, Blyth F, Buchbinder R. The Epidemiology of low back pain. Best Pract Res Clin Rheumatol 2010;24:769-81.

[30] Knight T, Schaefer C, Chandran A, Zlateva G, Winkelmann A, Perrot S. Health-resource use and costs associated with fibromyalgia in France, Germany, and the United States. Clinicoecon Outcomes Res 2013;5: $171-80$.

[31] Lalonde L, Choiniere M, Martin E, Berbiche D, Perreault S, Lussier D. Costs of moderate to severe chronic pain in primary care patients-a study of the ACCORD Program. J Pain Res 2014;7:389-403.

[32] Leadley RM, Armstrong N, Reid KJ, Allen A, Misso KV, Kleijnen J. Healthy Aging in Relation to Chronic Pain and Quality of Life in Europe. Pain Pract 2013;14:547-58. 
[33] Leboeuf-Yde C, Nielsen J, Kyvik KO, Fejer R, Hartvigsen J. Pain in the lumbar, thoracic or cervical regions: do age and gender matter? A population-based study of 34,902 Danish twins 20-71 years of age. BMC Musculoskelet Disord 2009;10:39.

[34] Miranda VS, Decarvalho VB, Machado LA, Dias JM. Prevalence of chronic musculoskeletal disorders in elderly Brazilians: a systematic review of the literature. BMC Musculoskelet Disord 2012;13:82.

[35] Molton IR, Terrill AL. Overview of persistent pain in older adults. Am Psychol 2014;69:197-207.

[36] Moore RA, Straube S, Aldington D. Pain measures and cut-offs - 'no worse than mild pain' as a simple, universal outcome. Anaesthesia 2013; 68:400-12.

[37] Nygaard Andersen L, Kohberg M, Juul-Kristensen B, Gram Herborg L, Soogard K, Roessler K. Psychosocial aspects of everyday life with chronic musculoskeletal pain: a systematic review. Scand J Pain 2014; 5:131-48

[38] Parker L, Moran GM, Roberts LM, Calvert M, McCahon D. The burden of common chronic disease on health-related quality of life in an elderly community-dwelling population in the UK. Fam Pract 2014;31:557-63.

[39] Pedisic Z, Pranic S, Jurakic D. Relationship of back and neck pain with quality of life in the Croatian general population. J Manipulative Physiol Ther 2013;36:267-75.

[40] Raftery MN, Sarma K, Murphy AW, De la Harpe D, Normand C, McGuire BE. Chronic pain in the Republic of Ireland-community prevalence, psychosocial profile and predictors of pain-related disability: results from the Prevalence, Impact and Cost of Chronic Pain (PRIME) study, part 1. PAIN 2011;152:1096-103.

[41] Rezai M, Cote P, Cassidy JD, Carroll L. The association between prevalent neck pain and health-related quality of life: a cross-sectional analysis. Eur Spine J 2009;18:371-81.

[42] Robinson ME, Brown JL, George SZ, Edwards PS, Atchison JW, Hirsh AT, Waxenberg LB, Wittmer V, Fillingim RB. Multidimensional success criteria and expectations for treatment of chronic pain: the patient perspective. Pain Med 2005;6:336-45.

[43] Sjogren P, Ekholm O, Peuckmann V, Gronbaek M. Epidemiology of chronic pain in Denmark: an update. Eur J Pain 2009;13:287-92.

[44] Swedish Council on Health Technology Assessment (SBU). Methods for treatment of chronic pain-a systematic review (In swedish). Stockholm, 2006.

[45] Thomas E, Mottram S, Peat G, Wilkie R, Croft P. The effect of age on the onset of pain interference in a general population of older adults: prospective findings from the North Staffordshire Osteoarthritis Project (NorStOP). PAIN 2007;129:21-7.

[46] Thomsen AB, Sorensen J, Sjogren P, Eriksen J. Chronic non-malignant pain patients and health economic consequences. Eur J Pain 2002;6: 341-52.

[47] Turk DC, Dworkin RH, Revicki D, Harding G, Burke LB, Cella D, Cleeland CS, Cowan P, Farrar JT, Hertz S, Max MB, Rappaport BA. Identifying important outcome domains for chronic pain clinical trials: an IMMPACT survey of people with pain. PAIN 2008;137:276-85.

[48] Vos T, Flaxman AD, Naghavi M, Lozano R, Michaud C, Ezzati M, Shibuya K, Salomon JA, Abdalla S, Aboyans V, Abraham J, Ackerman I, Aggarwal R, Ahn SY, Ali MK, Alvarado M, Anderson HR, Anderson LM, Andrews KG, Atkinson C, Baddour LM, Bahalim AN, Barker-Collo S, Barrero LH, Bartels DH, Basáñez MG, Baxter A, Bell ML, Benjamin EJ, Bennett D, Bernabé E, Bhalla K, Bhandari B, Bikbov B, Bin Abdulhak A, Birbeck G, Black JA, Blencowe $H$, Blore JD, Blyth F, Bolliger I, Bonaventure A, Boufous S, Bourne R, Boussinesq M, Braithwaite T, Brayne C, Bridgett L, Brooker S, Brooks P, Brugha TS, Bryan-Hancock C, Bucello C, Buchbinder R, Buckle G, Budke CM, Burch M, Burney P, Burstein R, Calabria B, Campbell B, Canter CE, Carabin H, Carapetis J, Carmona L,
Cella C, Charlson F, Chen H, Cheng AT, Chou D, Chugh SS, Coffeng LE, Colan SD, Colquhoun S, Colson KE, Condon J, Connor MD, Cooper LT, Corriere M, Cortinovis M, de Vaccaro KC, Couser W, Cowie BC, Criqui MH, Cross M, Dabhadkar KC, Dahiya M, Dahodwala N, Damsere-Derry J, Danaei G, Davis A, De Leo D, Degenhardt L, Dellavalle R, Delossantos A, Denenberg J, Derrett S, Des Jarlais DC, Dharmaratne SD, Dherani M, Diaz-Torne C, Dolk H, Dorsey ER, Driscoll T, Duber H, Ebel B, Edmond K, Elbaz A, Ali SE, Erskine H, Erwin PJ, Espindola P, Ewoigbokhan SE, Farzadfar F, Feigin V, Felson DT, Ferrari A, Ferri CP, Fèvre EM, Finucane MM, Flaxman S, Flood L, Foreman K, Forouzanfar MH, Fowkes FG, Franklin R, Fransen M, Freeman MK, Gabbe BJ, Gabriel SE, Gakidou E, Ganatra HA, Garcia B, Gaspari F, Gillum RF, Gmel G, Gosselin R, Grainger R, Groeger J, Guillemin F, Gunnell D, Gupta R, Haagsma J, Hagan H, Halasa YA, Hall W, Haring D, Haro JM, Harrison JE, Havmoeller R, Hay RJ, Higashi H, Hill C, Hoen B, Hoffman H, Hotez PJ, Hoy D, Huang JJ, lbeanusi SE, Jacobsen KH, James SL, Jarvis D, Jasrasaria R, Jayaraman S, Johns $N$, Jonas JB, Karthikeyan G, Kassebaum N, Kawakami N, Keren A, Khoo JP, King CH, Knowlton LM, Kobusingye O, Koranteng A, Krishnamurthi R, Lalloo R, Laslett LL, Lathlean T, Leasher JL, Lee YY, Leigh J, Lim SS, Limb E, Lin JK, Lipnick M, Lipshultz SE, Liu W, Loane M, Ohno SL, Lyons R, Ma J, Mabweijano J, Maclntyre MF, Malekzadeh R, Mallinger L, Manivannan S, Marcenes W, March L, Margolis DJ, Marks GB, Marks R, Matsumori A, Matzopoulos R, Mayosi BM, McAnulty JH, McDermott MM, McGill N, McGrath J, Medina-Mora ME, Meltzer M, Mensah GA, Merriman TR, Meyer AC, Miglioli V, Miller M, Miller TR, Mitchell PB, Mocumbi AO, Moffitt TE, Mokdad AA, Monasta L, Montico M, MoradiLakeh M, Moran A, Morawska L, Mori R, Murdoch ME, Mwaniki MK, Naidoo K, Nair MN, Naldi L, Narayan KM, Nelson PK, Nelson RG, Nevitt MC, Newton CR, Nolte S, Norman P, Norman R, O'Donnell M, O'Hanlon S, Olives C, Omer SB, Ortblad K, Osborne R, Ozgediz D, Page A, Pahari B, Pandian JD, Rivero AP, Patten SB, Pearce N, Padilla RP, Perez-Ruiz F, Perico N, Pesudovs K, Phillips D, Phillips MR, Pierce K, Pion S, Polanczyk GV, Polinder S, Pope CA III, Popova S, Porrini E, Pourmalek F, Prince M, Pullan RL, Ramaiah KD, Ranganathan D, Razavi H, Regan M, Rehm JT, Rein DB, Remuzzi G, Richardson K, Rivara FP, Roberts T, Robinson C, De Leòn FR, Ronfani L, Room R, Rosenfeld LC, Rushton L, Sacco RL, Saha S, Sampson U, Sanchez-Riera L, Sanman E, Schwebel DC, Scott JG, Segui-Gomez M, Shahraz S, Shepard DS, Shin H, Shivakoti R, Singh D, Singh GM, Singh JA, Singleton J, Sleet DA, Sliwa K, Smith E, Smith JL, Stapelberg NJ, Steer A, Steiner T, Stolk WA, Stovner LJ, Sudfeld C, Syed S, Tamburlini G, Tavakkoli M, Taylor HR, Taylor JA, Taylor WJ, Thomas B, Thomson WM, Thurston GD, Tleyjeh IM, Tonelli M, Towbin JA, Truelsen T, Tsilimbaris MK, Ubeda C, Undurraga EA, van der Werf MJ, van Os J, Vavilala MS, Venketasubramanian N, Wang M, Wang W, Watt K, Weatherall DJ, Weinstock MA, Weintraub R, Weisskopf MG, Weissman MM, White RA, Whiteford H, Wiersma ST, Wilkinson JD, Williams HC, Williams SR, Witt E, Wolfe F, Woolf AD, Wulf S, Yeh PH, Zaidi AK, Zheng ZJ, Zonies D, Lopez AD, Murray CJ, AlMazroa MA, Memish ZA. Years lived with disability (YLDs) for 1160 sequelae of 289 diseases and injuries 1990-2010: a systematic analysis for the Global Burden of Disease Study 2010. Lancet 2012;380:2163-96.

[49] Weisbrod B. The valuation of human capital. J Polit Economy 1961;51: $1-17$.

[50] Wirehn A, Karlsson H, Carstensen J. Estimating disease prevalence using a population-based administrative healthcare database. Scand J Public Health, 2007;35:424-31.

[51] Yamada K, Matsudaira K, Takeshita K, Oka H, Hara N, Takagi Y. Prevalence of low back pain as the primary pain site and factors associated with low health-related quality of life in a large Japanese population: a pain-associated cross-sectional epidemiological survey. Mod Rheumatol 2014;24:343-8. 